\title{
Association among duration of mechanical ventilation, cuff material of endotracheal tube, and postoperative nosocomial pneumonia in cardiac surgical patients: A prospective study
}

\author{
Jan Poelaert, $\mathrm{MD}, \mathrm{PhD},{ }^{\mathrm{a}}$ Patrick Haentjens, $\mathrm{MD}, \mathrm{PhD},{ }^{\mathrm{b}}$ and Stijn Blot, $\mathrm{PhD}^{\mathrm{c}}$
}

\begin{abstract}
Objectives: Postoperative pulmonary complications are a burden for high-risk surgical patients with a risk of aspiration of subglottic secretions along the polyvinyl chloride cuff. The introduction of a polyurethane cuff diminishes secretion leakage with a decreased rate of pneumonia. The aim of the current analysis was to determine the time at which a polyurethane cuffed endotracheal tube might be advantageous to prevent aspiration in a setting of high-risk surgical patients.
\end{abstract}

\begin{abstract}
Methods: The present investigation is based on published data obtained in postoperative cardiac surgical patients undergoing operation from 2006 to 2007. Cuff pressure was kept between 20 and $26 \mathrm{cmH} 2 \mathrm{O}$ intraoperatively and in the intensive care unit. The current post hoc analysis determines (1) the discriminatory cutoff value of intubation duration for predicting postoperative pneumonia and (2) the potential factors associated with prolonged intubation.
\end{abstract}

Results: Forty-three patients $(32 \%)$ were diagnosed with early postoperative pneumonia. Receiver operating characteristics analysis revealed a cutoff value of 16.6 hours for the duration of mechanical ventilation to discriminate patients with postoperative pneumonia. A stepwise binary logistic regression analysis revealed that a polyvinyl chloride cuff was associated with a 10-fold increased risk for prolonged intubation.

Conclusions: The current analyses provide evidence that among cardiac surgical patients, mechanical ventilation more than 16.6 hours is associated with an increased likelihood of postoperative pneumonia. (J Thorac Cardiovasc Surg 2014;148:1622-7)

Postoperative pulmonary infections are a major cause of prolonged hospital care, particularly in high-risk surgical patients. ${ }^{1-3}$ Accumulation of secretions in the subglottic area has been described as a major cause. Leakage of secretions along an inadequately sealing cuff and little channels, due to the physical characteristics of a polyvinyl chloride (PVC) cuff, could cause postoperative pneumonia. $^{4-6}$ Indeed, microaspiration has been associated with ventilator-associated tracheobronchitis and pneumonia. ${ }^{7,8}$ In this respect, evident preventive intraoperative measures comprise adequate cuff pressure and sealing optimization of the endotracheal cuff.

During the past years, there has been considerable progress by optimizing the cuff material altering from PVC to polyurethane (PU) ${ }^{9-11}$ The physical characteristics of PU

From the Department of Anesthesiology and Perioperative Medicine, ${ }^{a}$ Faculty of Medicine and Pharmacology, Vrije Universiteit Brussel, Brussels, Belgium; Center for Outcomes Research and Laboratory for Experimental Surgery, ${ }^{\mathrm{b}}$ Universitair Ziekenhuis Brussel, Vrije Universiteit Brussel, Brussels, Belgium; and Department of Internal Medicine, ${ }^{\mathrm{c}}$ Ghent University, Ghent, Belgium.

Disclosures: Authors have nothing to disclose with regard to commercial support.

Received for publication May 21, 2013; revisions received April 28, 2014; accepted for publication May 29, 2014; available ahead of print Aug 13, 2014.

Address for reprints: Jan Poelaert, MD, PhD, Department of Anesthesiology and

Perioperative Medicine, University Hospital, Laarbeeklaan 101, 1090 Brussels,

Belgium (E-mail: Jan.poelaert@uzbrussel.be).

0022-5223/\$36.00

Copyright $($ C 2014 by The American Association for Thoracic Surgery

http://dx.doi.org/10.1016/j.jtcvs.2014.05.085 allow the formation of smaller channels, considerably improving sealing capacity and preventing descent of subglottic secretions into the trachea. Poelaert and colleagues ${ }^{11}$ have demonstrated a significant decline in the occurrence rate of pneumonia.

Knowledge of the time frame when a PU-cuffed endotracheal tube (ET) becomes beneficial would be important for anesthesiologists and critical care physicians. Therefore, the aim of the current analysis was to determine the time point before which a PU cuffed ET might become advantageous to prevent aspiration in a setting of high-risk surgical patients. Therefore, we used data from our previously published randomized, controlled trial comparing PVC with PU cuffed ETs. ${ }^{11}$ More specifically, the objectives of the current post hoc analysis were as follows: (1) to determine the discriminatory cutoff value of duration of intubation predicting postoperative nosocomial pneumonia and (2) to determine which factors are associated with prolonged duration of intubation.

\footnotetext{
METHODS

The current post hoc analysis is based on a series of patients (undergoing operation in 2006-2007) who were enrolled in a previously published randomized, controlled trial studying the effects of cuff material (PVC vs PU cuffed tubes) on the incidence of early postoperative pneumonia after major heart surgery. ${ }^{11}$ The investigation was approved by the ethics committee at Ghent University Hospital (2005/098), and all patients provided written consent to participate in the study.
} 

Abbreviations and Acronyms
ET = endotracheal tube
euroSCORE $=$ European System for Cardiac
Operative Risk Evaluation
ICU = intensive care unit
IV $\quad=$ intravenously
$\mathrm{PU} \quad=$ polyurethane
PVC = polyvinyl chloride
ROC $=$ receiver operating characteristic

The study design of the randomized, controlled trial comparing PVC with PU cuffed tubes has been reported. ${ }^{11}$ Briefly, all patients undergoing scheduled, urgent, or emergency major heart surgery-coronary revascularization, valve surgery, or combined surgical interventions-were included. Patients with previous ( $<1$ month) or current antibiotic treatment were excluded. Therefore, all patients with endocarditis were not included.

All enrolled patients underwent cardiac surgery after intubation randomly with a high-volume, low-pressure PVC barrel-shaped cuffed (Malinckrodt Inc, Hazelwood, Mo) or PU barrel-shaped cuffed (Sealguard; Covidien, Mansfield, Mass) ET at induction of the anesthetic. The choice of tube used was governed by a randomization list. The anesthesiologist was the sole caregiver aware of which tube was placed into the trachea. Both the PVC and the PU cuffed ET looked similar once the patient was intubated. Therefore, none of the involved caregivers could discern the different tubes. According to countrywide accepted current guidelines, female patients received an ET with an 8.0-mm internal diameter and male patients received an ET with a 9.0-mm internal diameter. After intubation, the cuff was inflated until cuff pressures were between 20 and $26 \mathrm{cmH} 2 \mathrm{O}$, which were assessed intermittently throughout the procedure and in the postoperative setting.

Induction of anesthesia was performed with sufentanil administered intravenously (IV) $\left(3 \mu \mathrm{g} \cdot \mathrm{kg}^{-1}\right)$ and propofol administered IV $\left(2 \mathrm{mg} \cdot \mathrm{kg}^{-1}\right)$, in addition to cis-atracurium (induction bolus IV $0.1 \mathrm{mg} \cdot \mathrm{kg}^{-1}$, after which a continuous infusion of $0.1 \mathrm{mg} \cdot \mathrm{kg}^{-1} \cdot \mathrm{h}^{-1}$ was administered). Antibiotic prophylaxis was obtained with cefazolin $2 \mathrm{~g} / 8$ hours administered IV for 24 hours.

Postoperatively, patients were transferred to an 8-bed postsurgical intensive care unit (ICU). Sedation consisted of propofol 0.5 to $2 \mathrm{mg} \cdot \mathrm{kg}^{-1} \cdot \mathrm{h}^{-1}$ administered IV, as reported previously by our research group. ${ }^{12}$ Cuff pressure was assessed on arrival and further evaluated at 4-hour intervals. Cuff pressure was kept between 20 and $26 \mathrm{cmH} 2 \mathrm{O}$. Ranitidine (50 mg IV 3 times per day), nitroglycerin $\left(0.25-1.0 \mu \mathrm{g} \cdot \mathrm{kg}^{-1} \cdot \mathrm{min}^{-1}\right)$, cefazolin 100 $\mathrm{mg} \cdot \mathrm{kg}^{-1} \cdot \mathrm{d}^{-1}$ (3 times per day), and inotropic drugs, when necessary, were administered. Weaning and extubation criteria consisted of cardiorespiratory stability, with adequate gas exchange, including an arterial oxygen tension greater than $70 \mathrm{~mm} \mathrm{Hg}$ (with inspired oxygen fraction $<0.6$, positive end-expiratory pressure $<6 \mathrm{cmH} 2 \mathrm{O}$, and peak inspiratory pressure $<21 \mathrm{cmH} 2 \mathrm{O}$ ), $\mathrm{pH}$ greater than 7.32 , and chest tube drainage less than $1 \mathrm{~mL} \cdot \mathrm{kg}^{-1} \cdot \mathrm{h}^{-1}$ for a minimum of 2 consecutive hours. In addition, any neurologic deficit was absent. Aspiration of oropharyngeal secretions was performed every 2 hours until extubation.

Bacteriological samples were taken routinely on arrival to the ICU. Furthermore, recruiting with a peak inspiratory pressure of $35 \mathrm{cmH} 2 \mathrm{O}$ and $5 \mathrm{cmH} 2 \mathrm{O}$ positive end-expiratory pressure was performed starting immediately postoperatively and subsequently every 2 hours, the last time just before extubation.

All other interventions and therapies were started and continued at the discretion of the attending anesthesiologist and surgical team. In all patients, routine blood samples including blood gases were assessed every 4 hours for the first 8 hours postoperatively, and later every 8 hours.
A control chest x-ray was taken postoperatively whenever it was found necessary by the attending intensive care physician and in any case the morning after operation. The European System for Cardiac Operative Risk Evaluation (euroSCORE) was calculated and chest x-rays were evaluated by an independent investigator.

Diagnosis of postoperative nosocomial pneumonia was defined before the onset of the study. In our patient population, because microbial pathogens other than commensal flora are rarely isolated in this setting of early postoperative pneumonia, we aimed for higher specificity of the clinical diagnosis requiring that all Johanson criteria ${ }^{13}$ and 2 additional criteria be fulfilled. ${ }^{14}$ Thus, postoperative nosocomial pneumonia was defined as the presence of a new or evolving infiltrate on chest $\mathrm{x}$-ray within 7 days after surgery, in conjunction with the presence of the Johanson criteria $^{13}$ : temperature greater than $38.2^{\circ} \mathrm{C}$, leukocytosis greater than 12,000 cells $/ \mathrm{mm}^{3}$, and presence of purulent sputum or endotracheal aspirate.

Additional criteria were an increase in C-reactive protein for at least 2 consecutive days after surgery and a deterioration of at least $20 \%$ of the ratio of arterial oxygen tension to the inspired oxygen fraction. After admission to the ICU, patients were screened daily for postoperative nosocomial pneumonia by the attending ICU physician, who was blinded to the ET allocation. Diagnosis of pneumonia was made during the stay in the ICU by the same staff intensive care physician.

\section{Statistical Analysis}

The diagnosis of the presence of postoperative pneumonia based on the duration of ventilation was explored using receiver operating characteristic (ROC) curves. By using the duration of ventilation of each patient, we calculated the ROC including area under the curve, specificities, sensitivities, and Youden's index J, which was obtained from the following formula $^{15}: \mathbf{J}=$ specificity + sensitivity -1 . The maximal value of Youden's index J corresponds to the optimal cutoff value for duration of ventilation to separate patients with and without postoperative pneumonia.

Next, patients were stratified into 2 distinct groups according to the optimal cutoff value for duration of ventilation as obtained from the maximal value of Youden's index J. For each group of interest, continuous data were summarized as median, indicating both 25 th and 75 th percentiles, and categoric data as the number of cases with percentage. Univariate between-group differences were analyzed by independent samples Mann-Whitney $U$ tests for continuous data and the Fisher exact or chi-square tests for categoric data. Statistical significance was specified as a 2 -tailed type I error ( $P$ value) set below the $5 \%$ level $(\alpha<.05)$.

A multivariate (binary logistic regression) analysis was carried out to assess independent risk factors for a mechanical ventilation duration in excess of the cutoff value (outcome variable). In this multivariate analysis, all variables with a $P$ value less than .15 in the univariate analysis were considered to have a plausible relationship with prolonged mechanical ventilation and were included in the adjusted equation model.

Variables were excluded stepwise if the $P$ value was greater than .15 in the adjusted equation. The euroSCORE remained included irrespective of its associated $P$ value because of its overall evaluation potential because this variable encompasses various physiologic variables. Adjusted odds ratios and $95 \%$ confidence intervals were calculated. All analyses were performed using SPSS version 20.0 (IBM, Chicago, Ill).

\section{RESULTS}

Overall, 136 patients were enrolled. Two patients died of refractory cardiogenic shock during surgery and were excluded from further analysis. ${ }^{11}$ The patient characteristics have been reported. Forty-three patients $(32 \%)$ were diagnosed with early postoperative pneumonia. The current post hoc ROC analysis revealed an area under the curve of 
TABLE 1. Characteristics of patients stratified according to duration of mechanical ventilation after cardiac surgery, as determined by the calculated cutoff value (Youden's index)

\begin{tabular}{|c|c|c|c|}
\hline & $\begin{array}{c}\text { Variable } \\
<16.6 \mathrm{~h}(\mathrm{n}=78)\end{array}$ & $\begin{array}{l}>16.6 \mathrm{~h} \\
(\mathrm{n}=58)\end{array}$ & $\boldsymbol{P}^{*}$ \\
\hline Age (y) & $69(24 ; 30)$ & $73(65 ; 76)$ & .06 \\
\hline Gender (male) (\%) & 56 & 76 & $<.001$ \\
\hline BMI $\left(\mathrm{kg} / \mathrm{m}^{2}\right)$ & $27(24 ; 30)$ & $26(23 ; 30)$ & .30 \\
\hline $\mathrm{EF}$ & $0.66(0.60 ; 0.78)$ & $0.60(0.45 ; 0.71)$ & .03 \\
\hline ECC duration (min) & $64(0 ; 90)$ & $71(0 ; 105)$ & .21 \\
\hline Duration ventilation (h) & $13(12 ; 15)$ & $21(19 ; 28)$ & $<.01$ \\
\hline Creatinine (mg/dL) & $0.99(0.82 ; 1.20)$ & $1.08(0.90 ; 1.36)$ & .02 \\
\hline euroSCORE & $4(2 ; 7)$ & $6(3 ; 8)$ & $<.01$ \\
\hline Diabetes $(\%)$ & 35 & 34 & .14 \\
\hline COPD $(\%)$ & 11 & 15 & .33 \\
\hline $\begin{array}{l}\text { Chronic renal failure } \\
\text { (RIFLE class F) (\%) }\end{array}$ & 21 & 35 & .06 \\
\hline LOS ICU (d) & $1.2(0.9 ; 2.8)$ & $1.9(1.0 ; 3.0)$ & .01 \\
\hline LOS hospital (d) & $12(10 ; 16)$ & $14(12 ; 20)$ & .05 \\
\hline Cuff PU & $42(55 \%)$ & $23(40 \%)$ & $<.01$ \\
\hline
\end{tabular}

Data are shown as median (25th percentile; 75 th percentile). BMI, Body mass index; $C O P D$, chronic obstructive pulmonary disease; $E C C$, extracorporeal circulation; $E F$, ejection fraction; euroSCORE, European System for Cardiac Operative Risk Evaluation; $I C U$, intensive care unit; $L O S$, length of stay; $P U$, polyurethane; RIFLE, Risk, Injury, Failure, Loss, and End-stage kidney disease. *Mann-Whitney $U$ test used for continuous variables, and Fisher exact or chi-square tests used for dichotomous variables.

0.63 (95\% confidence interval, $0.52-0.74 ; P=.022)$, and a maximal Youden's $\mathrm{J}$ index of .258. This maximal index relates to the cutoff value of duration of ventilation to discriminate patients with and without postoperative pneumonia in the ICU. The cutoff value appeared to be maximal at 16.6 hours of mechanical ventilation after cardiac surgery. After these findings, we stratified the patients into 2 groups (Table 1). Those patients requiring ventilatory support for more than 16.6 hours seemed to be slightly older, to be sicker preoperatively, and to have longer ICU and hospital stays. More male patients required prolonged ventilation after cardiac surgery. Patients intubated with a PU cuffed ET were more common in the group that was ventilated less than 16.63 hours. Comorbidities, such as diabetes, chronic obstructive pulmonary disease, or pulmonary hypertension, were not associated with early postoperative pneumonia.

Table 2 shows some relevant perioperative information that may influence the incidence of pneumonia. The duration of surgery or cardiopulmonary bypass time did not differ significantly. Blood product consumption was not different between the subsets of patients. Only ventilation duration showed a tendency to differ considering the pneumonia rate in the PVC cuffed versus the PU cuffed subset. Reexploration was necessary in 3 patients of the PVC subset and in 2 patients of the PU subset.

The data analysis of those patients ventilated more than 16.6 hours, as indicated by the Youden's index, intubated with a PU or PVC cuffed tube, is shown in Table 3. None of the variables showed any statistical significance. However, by looking more closely at the data, it appears that 5 of 33 patients in the PVC subset were ventilated 60 hours or more versus 1 of 22 patients in the PU group $(P=.03)$.

A stepwise binary logistic regression analysis showed that cuff material (PVC) was the strongest statistically significant $(P=.01)$ factor determining prolonged duration of ventilation (Table 4). The choice of a PVC cuffed ET is characterized by an approximately 11-fold risk of prolonged ventilation after cardiac surgery in these critically ill patients. Acute kidney injury, defined by an increased creatinine level $(\geq 1.2 \mathrm{mg} / \mathrm{dL}$ or $>\times 1.5$ from baseline), was associated with an increased risk (2.5-fold) for prolonged ventilator support after cardiac surgery, but this finding did not reach statistical significance

TABLE 2. Comparison between patients intubated with a polyvinyl chloride or polyurethane cuffed endotracheal tube; presence of postoperative pneumonia is indicated

\begin{tabular}{|c|c|c|c|c|c|c|c|}
\hline \multirow[b]{2}{*}{ Pneumonia (no.) } & \multicolumn{2}{|c|}{ PVC (67) } & \multirow{2}{*}{$\frac{P \text { value }}{<.01}$} & \multicolumn{2}{|c|}{ PU (67) } & \multirow{2}{*}{$\frac{P \text { value }}{<.01}$} & \multirow{2}{*}{$\frac{\boldsymbol{P} \text { value }^{*}}{<.01}$} \\
\hline & Yes (28) & No (39) & & Yes (14) & No (53) & & \\
\hline Age (y) & $74(67 ; 78)$ & $68(56 ; 77)$ & .04 & $74(65 ; 76)$ & $69(59 ; 75)$ & .30 & .82 \\
\hline BMI $\left(\mathrm{kg} / \mathrm{m}^{2}\right)$ & $27(23 ; 30)$ & $25(23 ; 28)$ & .18 & $28(26 ; 31)$ & $27(24 ; 30)$ & .27 & .56 \\
\hline Preoperative LVEF (\%) & $60(47 ; 68)$ & $68(50 ; 72)$ & .20 & $60(47 ; 66)$ & $67(60 ; 79)$ & .23 & .60 \\
\hline euroSCORE & $7(3 ; 8)$ & $4(2 ; 7)$ & .03 & $6(2 ; 11)$ & $4(2 ; 7)$ & .03 & .68 \\
\hline Diabetes mellitus ( $\%$ in subset) & 29 & 23 & .15 & 47 & 30 & $<.01$ & $<.01$ \\
\hline Surgery (min) & $240(233 ; 270)$ & $263(225 ; 300)$ & .98 & $240(206 ; 278)$ & $2505(184 ; 300)$ & .93 & .53 \\
\hline ECC time (min) & $68(0 ; 102)$ & $71(53 ; 102)$ & .73 & $70(0 ; 121)$ & $69(0 ; 93)$ & .09 & $<.01$ \\
\hline Duration of ventilation (h) & $17(13 ; 28)$ & $16(12 ; 30)$ & .04 & $14(12 ; 28)$ & $16(13 ; 20)$ & .59 & .23 \\
\hline LOS in ICU (d) & $2.8(1.8 ; 4.0)$ & $1.0(0.9 ; 2.0)$ & $<.01$ & $2.8(1.6 ; 2.9)$ & $1.1(0.9 ; 2.6)$ & .08 & .45 \\
\hline LOS in hospital (d) & $15(12 ; 22)$ & $11(10 ; 16)$ & .04 & $14(10 ; 30)$ & $13(10 ; 15)$ & .08 & .78 \\
\hline Packed red blood cells (Units) & $1(0 ; 2)$ & $0(0 ; 1)$ & .01 & $1(0 ; 2)$ & $0(0 ; 2)$ & .25 & .36 \\
\hline
\end{tabular}

Data are shown as median value (25th percentile; 75th percentile). BMI, Body mass index; ECC, extracorporeal circulation; euroSCORE, European System for Cardiac Operative Risk Evaluation; $L O S$, length of stay; $L V E F$, left ventricular ejection fraction; $P U$, polyurethane; $P V C$, polyvinyl chloride; $I C U$, intensive care unit. *This column concerns the statistical results of the comparison between patients with pneumonia who were intubated with a PVC or PU cuffed ET. There was no statistical significance between the subsets of patients without pneumonia. 
TABLE 3. Comparison of patients with a need for postoperative prolonged ventilatory support $(>16.6$ hours of ventilation) and intubated with a polyvinyl chloride or polyurethane cuffed endotracheal tube

\begin{tabular}{lccr}
\hline & PVC $(\mathbf{n}=\mathbf{6 7})$ & PU $(\mathbf{n}=\mathbf{6 7})$ & \multicolumn{1}{c}{$\boldsymbol{P}$} \\
\hline $\mathrm{n}$ & 33 & 22 & $<.01$ \\
Age $(\mathrm{y})$ & $75(66 ; 79)$ & $72(59 ; 76)$ & .56 \\
$\mathrm{BMI}$ & $25(22 ; 30)$ & $27(24 ; 32)$ & .52 \\
EF $(\%)$ & $60(48 ; 71)$ & $61(45 ; 70)$ & .09 \\
Duration of intervention & $270(240 ; 300)$ & $263(229 ; 300)$ & .09 \\
$\quad($ min) & & & \\
Duration of ventilation (h) & $21(18 ; 28)$ & $22(20 ; 30)$ & .31 \\
Creatinine (mg/dL) & $1.08(0.88 ; 1.35)$ & $1.08(0.95 ; 1.46)$ & .86 \\
euroSCORE & $7(3 ; 10)$ & $4(2 ; 7)$ & .21 \\
COPD (\%) & 16 & 14 & .56 \\
Diabetes mellitus (\%) & 25 & 23 & .63 \\
Chronic renal failure $(\%)$ & 28 & 41 & $<.01$ \\
LOS ICU (d) & $1.9(1.0 ; 3.1)$ & $2.0(1.0 ; 2.9)$ & .50 \\
LOS hospital (d) & $16(12 ; 21)$ & $13(11 ; 17)$ & .24 \\
\hline
\end{tabular}

Data are shown as median value (25th percentile; 75 th percentile). $B M I$, Body mass index; $C O P D$, chronic obstructive pulmonary disease; $E F$, ejection fraction; euroSCORE, European System for Cardiac Operative Risk Evaluation; $I C U$, intensive care unit; $L O S$, length of stay; $P U$, polyurethane; $P V C$, polyvinyl chloride.

$(P=.12)$. The euroSCORE, gender, and preoperative ejection fraction did not reach levels of significance in this analysis.

\section{DISCUSSION}

The results of the present investigation clearly show that a critical time point can be assigned after which a PU cuffed ET seems protective against early postoperative pneumonia. At more than 16.6 hours of postoperative ventilation, more cardiac surgical patients who were intubated with a PVC cuffed ET required ventilator support. Postoperative pneumonia after cardiac surgery-both in adults ${ }^{16,17}$ and after congenital cardiac surgery ${ }^{18}$-is one of the risk factors impeding rapid weaning and extubation. It is to be expected that the most critically ill patients require longer ventilatory support, considerably increasing the risk of morbidity and mortality. ${ }^{19}$ This is supported by the

TABLE 4. Independent risk factors associated with prolonged mechanical ventilation ( $>16.63$ hours) after cardiac surgery according to logistic regression analysis

\begin{tabular}{lrlc}
\hline \multicolumn{1}{c}{ Variable } & OR & \multicolumn{1}{c}{$\mathbf{9 5} \%$ CI } & $\boldsymbol{P}$ value \\
\hline Cuff material (PVC) & 10.94 & $1.73-69.29$ & .01 \\
Creatinine (mg/dL) & 2.51 & $0.78-8.07$ & .12 \\
euroSCORE (per point increase) & 1.22 & $0.97-1.54$ & .10 \\
\hline
\end{tabular}

Stepwise logistic regression analysis with duration of ventilation $>16.6$ hours as dependent (outcome) variable. Independent variables entered into the model were those found to be significant in the univariate analysis (Table 1): gender, preoperative ejection fraction, euroSCORE, preoperative creatinine level, and cuff material. The table lists those variables retained by the stepwise logistic regression analysis at a 15 level of significance. CI, Confidence interval; euroSCORE, European System for Cardiac Operative Risk Evaluation; $O R$, odds ratio; $P V C$, polyvinyl chloride.

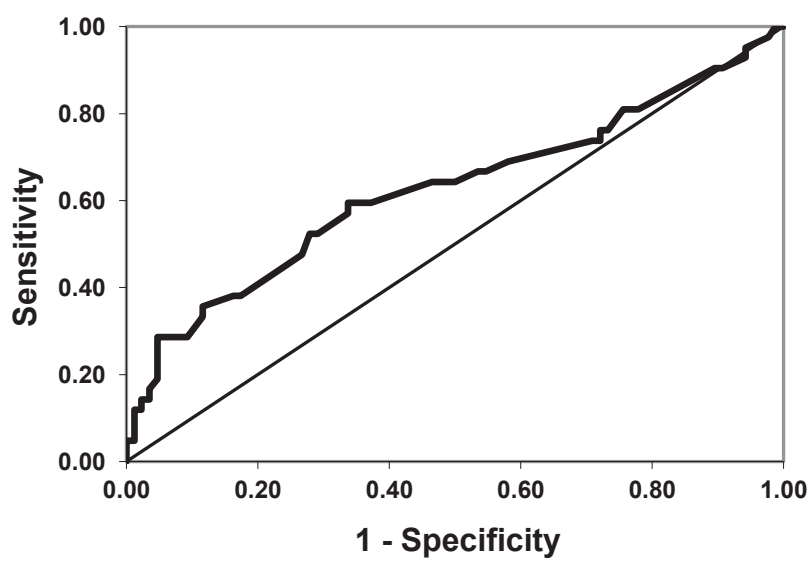

FIGURE 1. ROC curve (area under the curve, $0.63 ; 95 \%$ confidence interval, 0.51-0.74) with standard error of $0.057(P=.022)$. Hosmer-Lemeshow goodness of fit: chi-square $=7.57(P=.48)$.

results shown in Table 1. Nevertheless, it is also demonstrated that fewer patients intubated with a PU cuffed ET required prolonged ventilatory support, although their preoperative illness score (euroSCORE) was comparable to that of patients in the PVC subset. This study now shows fewer patients remain ventilated when intubated with a PU cuffed ET, but once over the time limit of 16.6 hours of postoperative ventilation, no obvious difference is present (Tables 2 and 3).

By combining the knowledge of high positive predictive value and positive specificity, we used the Youden's index to determine the increased risk of an early postoperative pulmonary infection in the presence of a PVC cuffed ET (Figure 1). The Youden's index allows defining cutoff values to distinguish patients with and without disease ${ }^{15}$ in case of postoperative pulmonary infection.

Prevention of postoperative pulmonary infections has been discussed extensively. Both animal ${ }^{20}$ and human ${ }^{21,22}$ studies suggest inflating the cuff to a pressure of 25 to 30 $\mathrm{cmH} 2 \mathrm{O}$. In the ICU, specific techniques are effective, such as subglottic aspiration, in reducing early-onset pneumonia rather than late pneumonia. ${ }^{10}$ However, the issue of leakage cannot be completely eliminated with traditional PVC cuffed ETs, ${ }^{6}$ leaving a major risk for postoperative pneumonia. ${ }^{9}$ In addition to continuous aspiration, improved sealing of the tracheal orifice could prevent further aspiration. In an in vitro study, Dullenkopf and colleagues ${ }^{9}$ demonstrated that sealing could be advanced by altering the material of the ET cuff. In an in vivo study in an ICU setting, Lorente and colleagues ${ }^{10}$ showed that optimization of tracheal sealing by introducing a PU-cuffed ET considerably reduced the rate of ventilator-associated pneumonia. Although this study used an ET combining continuous subglottic aspiration and PU cuff, the results were suggestive for beneficial effects of the PU cuff. In this respect, it has to be acknowledged that cuff pressure 
is an important issue. In a single blinded, randomized, prospective study, our research group demonstrated that the use of a PU cuffed ET (inflation pressure kept at $\pm 25 \mathrm{cmH} 2 \mathrm{O}$ ) reduced the rate of early postoperative pneumonia after cardiac surgery, even related to postoperative duration of mechanical ventilatory support. ${ }^{11}$ By using the same dataset, the present post hoc analysis shows that the risk for early postoperative pneumonia increases significantly beyond the time limit of 16.6 hours of mechanical ventilation in patients intubated with traditional PVC cuffed ETs. This timing has been obtained by calculating the Youden's index for postoperative pneumonia in the presence of a PVC cuffed ET.

Prevention of postoperative pulmonary infection is not just a matter of a tailored choice of an ET preoperatively; early stabilization of hemodynamics, fluid balance, cardiac function, optimal preload, and perfusion should be kept in mind. Nevertheless, preventive measures of respiratory infections need our attention in the critically ill, especially those undergoing cardiac surgery.

Therefore, patients at risk for postoperative pneumonia are those with low ejection fraction, in particular when hemodynamic instability and positive fluid balances are present. Table 2 alludes to this issue: Those patients with a preoperative higher euroSCORE and presence of renal insufficiency seem to benefit postoperatively from using a PU cuffed ET. The choice of cuff material interferes with the rate of pneumonia and the duration of postoperative mechanical ventilation (Table 2). The PU cuff partially impedes aspiration by the material characteristics: $\mathrm{PU}$ is thinner and more supple than PVC. ${ }^{9,11}$ Therefore, it could be expected that a more complete inflation of the cuff is possible, with improved tracheal sealing and less or absent channel formation along a PU cuff.

The different risk factors of aspiration have been elucidated in various settings. Arozullah and colleagues ${ }^{2}$ used a multifactorial risk index in noncardiac surgical patients at risk for postoperative pneumonia. In addition to the type of surgery, age, pulmonary status, transfusion, and functional status seemed to be the most important issues with respect to the development of postoperative pneumonia. ${ }^{2}$ The persistent need for a recumbent position in patients with long-lasting hemodynamic instability is a major issue postoperatively in cardiac surgical patients. In addition, decreased immunologic defense after cardiopulmonary bypass has been recognized as a major cause of increased frequency of postoperative infections after cardiac surgery. ${ }^{23,24}$ Manipulations of the transesophageal probe during echocardiography with causing potential pharyngeal secretions and swallowing dysfunction $^{25}$ could be an impending factor of ventilatorassociated tracheobronchitis. ${ }^{14}$

The current analysis shows that patients already are at risk after 16.6 hours of intubation with a PVC cuffed ET, whereas the PU subset of patients showed far less frequent an evolution toward early postoperative pneumonia (Table 3). The material of the cuff of the ET is only one aspect. Early preventive measures ${ }^{26}$ such as preoperative rinsing with chlorhexidine ${ }^{27}$ and choice of tube, ${ }^{10,28,29}$ are to be added in view of the expected time for ventilatory support to prevent the development of postoperative pneumonia.

\section{Study Limitations}

The absence of positive microbiological results on admission to the ICU in all but 16 patients demonstrates the difficulty of obtaining adequate bacteriological cultures to support the relationship between infection and oropharyngeal colonization, as reported by others. ${ }^{30-32}$ Similar difficulties were encountered when discriminating data on the relationship of ventilator-associated tracheobronchitis and early postoperative pneumonia. ${ }^{33}$ The lack of microbiological confirmation of early postoperative pneumonia in the present investigation could be related to several issues: Several patients were already extubated when the clinical diagnosis of early postoperative pneumonia was considered, hampering the proper isolation of microbial pathogens. Standard prophylactic use of antibiotics (cefazolin) intraoperatively and the first 24 hours postoperatively impeded more positive microbial cultures. In addition, several authors have stressed the fact that early postoperative pneumonia is based on a primarily clinical diagnosis, ${ }^{30,32,34}$ particularly because supplementary diagnostic tests were not applicable or not available in a postoperative cardiac surgical setting. Postoperative patients often lack preventive measures intraoperatively with persistent recumbent or even Trendelenburg positioning. Furthermore, cuff pressure was not assessed continuously but using a 4-hour interval schedule. This methodology could imply a potential loss of air with each disconnection of the syringe, ${ }^{35}$ less optimal sealing, and thus an increase in the aspiration risk. However, even with an optimal cuff pressure, it has been demonstrated that leakage along the PVC cuff is still possible and occurs in a high percentage of patients. ${ }^{9}$ Variations in cuff pressure might even take place after minimal body position changes. ${ }^{36}$

Finally, data from the original file were taken, which inherently has a limitation, for example, in not using the most recent scoring systems: We used euroSCORE I instead of euroSCORE II. Patients may have been managed differently than contemporary patients, although in practice no important changes in the perioperative care of cardiac surgical patients could be expected.

\section{CONCLUSIONS}

The current report denotes an unambiguous time point (at 16.6 hours) of mechanical ventilation after cardiac 
surgery, beyond which PU cuffed ETs protect patients from developing early postoperative pneumonia more efficiently than PVC cuffed ETs. The introduction of other devices, such as taper-shaped cuffed ETs, could shed light on the prevention of postoperative and ventilator-associated pneumonia. Larger studies are needed to discern whether these results are applicable to a general ICU population with long-term ventilation.

\section{References}

1. Rebollo MH, Bernal JM, Llorca J, Rabasa JM, Revuelta JM. Nosocomial infections in patients having cardiovascular operations: a multivariate analysis of risk factors. J Thorac Cardiovasc Surg. 1996;112:908-13.

2. Arozullah AM, Khuri SF, Henderson WG, Daley J. Development and validation of a multifactorial risk index for predicting postoperative pneumonia after major noncardiac surgery. Ann Intern Med. 2001;135:847-57.

3. Lawrence VA, Cornell JE, Smetana GW. Strategies to reduce postoperative pulmonary complications after noncardiothoracic surgery: systematic review for the American College of Physicians. Ann Intern Med. 2006; 144:596-608.

4. Zanella A, Scaravilli V, Isgrò S, Milan M, Cressoni M, Patroniti N, et al. Fluid leakage across tracheal tube cuff, effect of different cuff material, shape, and positive expiratory pressure: a bench-top study. Intensive Care Med. 2011; 37:343-7.

5. Dave MH, Frotzler A, Spielmann N, Madjdpour C, Weiss M. Effect of tracheal tube cuff shape on fluid leakage across the cuff: an in vitro study. Br J Anaesth. 2010;105:538-43

6. D'Haese J, De Keukeleire T, Remory I, Van Rompaey K, Umbrain V, Poelaert J. Assessment of intraoperative microaspiration: does a modified cuff shape improve sealing? Acta Anaesthesiol Scand. 2013;57:873-80.

7. Craven DE, Chroneou A, Zias N, Hjalmarson KI. Ventilator-associated tracheobronchitis. Chest. 2009;135:521-8.

8. Dallas J, Skrupky L, Abebe N, Boyle WA III, Kollef MH. Ventilator-associated tracheobronchitis in a mixed surgical and medical ICU population. Chest. 2011; 139:513-8.

9. Dullenkopf A, Gerber A, Weiss M. Fluid leakage past tracheal tube cuffs: evaluation of the new Microcuff endotracheal tube. Intensive Care Med. 2003; 29:1849-53.

10. Lorente L, Lecuona M, Jimenez A, Mora ML, Sierra A. Influence of an endotracheal tube with polyurethane cuff and subglottic secretion drainage on pneumonia. Am J Respir Crit Care Med. 2007;176:1079-83.

11. Poelaert J, Depuydt P, De Wolf A, Van de Velde S, Herck I, Blot S. Polyurethane cuffed endotracheal tubes to prevent early postoperative pneumonia after cardiac surgery: a pilot study. J Thorac Cardiovasc Surg. 2008;135:771-6.

12. Schmidt C, Roosens C, Struys M, Deryck Y, Van Nooten G, Colardyn F, et al. Contractility in humans after coronary artery surgery. Anesthesiology. 1999;91: 58-70.

13. Johanson WG Jr, Pierce AK, Sanford JP, Thomas GD. Nosocomial respiratory infections with gram-negative bacilli. The significance of colonization of the respiratory tract. Ann Intern Med. 1972;77:701-6.

14. Nseir S, Di Pompeo C, Soubrier S, Lenci H, Delour P, Onimus T, et al. Effect of ventilator-associated tracheobronchitis on outcome in patients without chronic respiratory failure: a case-control study. Crit Care. 2005;9:R238-45.

15. Bewick V, Cheek L, Ball J. Statistics review 9: one-way analysis of variance. Crit Care. 2004;8:130-6.

16. Bouza E, Perez A, Munoz P, Jesus Perez M, Rincon C, Sanchez C, et al. Ventilator-associated pneumonia after heart surgery: a prospective analysis and the value of surveillance. Crit Care Med. 2003;31:1964-70.
17. Iribarne A, Burgener JD, Hong K, Raman J, Akhter S, Easterwood R, et al Quantifying the incremental cost of complications associated with mitral valve surgery in the United States. J Thorac Cardiovasc Surg. 2012;143:864-72.

18. Shi S, Zhao Z, Liu X, Shu Q, Tan L, Lin R, et al. Perioperative Risk Factors for Prolonged Mechanical Ventilation Following Cardiac Surgery in Neonates and Young Infants. Chest. 2008;134:768-74.

19. Ghanta RK, Shekar PS, McGurk S, Rosborough DM, Aranki SF. Nonelective cardiac surgery in the elderly: is it justified? J Thorac Cardiovasc Surg. 2010; 140:130-9.e1.

20. Touzot-Jourde G, Stedman NL, Trim CM. The effects of two endotracheal tube cuff inflation pressures on liquid aspiration and tracheal wall damage in horses. Vet Anaesth Analg. 2005;32:23-9.

21. Dullenkopf A, Schmitz A, Frei M, Gerber AC, Weiss M. Air leakage around endotracheal tube cuffs. Eur J Anaesthesiol. 2004;21:448-53.

22. Sanjay PS, Miller SA, Corry PR, Russell GN, Pennefather SH. The effect of gel lubrication on cuff leakage of double lumen tubes during thoracic surgery. Anaesthesia. 2006;61:133-7.

23. Flohe S, Borgermann J, Lim L, Schade FU. Interferon-gamma counteracts reduced endotoxin responsiveness of whole blood following trauma and cardiopulmonary bypass. J Endotoxin Res. 2000;6:431-6.

24. van Oeveren W, Kazatchkine MD, Descamps-Latscha B, Maillet F, Fischer E, Carpentier A, et al. Deleterious effects of cardiopulmonary bypass. A prospective study of bubble versus membrane oxygenation. J Thorac Cardiovasc Surg. 1985; 89:888-99.

25. Hogue CW Jr, Lappas GD, Creswell LL, Ferguson TB Jr, Sample M, Pugh D et al. Swallowing dysfunction after cardiac operations. Associated adverse outcomes and risk factors including intraoperative transesophageal echocardiography. J Thorac Cardiovasc Surg. 1995;110:517-22.

26. Safdar N, Crnich CJ, Maki DG. The pathogenesis of ventilator-associated pneumonia: its relevance to developing effective strategies for prevention. Respir Care. 2005;50:725-39; discussion 39-41

27. Segers P, Speekenbrink RG, Ubbink DT, van Ogtrop ML, de Mol BA Prevention of nosocomial infection in cardiac surgery by decontamination of the nasopharynx and oropharynx with chlorhexidine gluconate: a randomized controlled trial. JAMA. 2006;296:2460-6.

28. Bouza E, Perez MJ, Munoz P, Rincon C, Barrio JM, Hortal J. Continuous aspiration of subglottic secretions in the prevention of ventilator-associated pneumonia in the postoperative period of major heart surgery. Chest. 2008; 134:938-46.

29. Kollef MH, Skubas NJ, Sundt TM. A randomized clinical trial of continuous aspiration of subglottic secretions in cardiac surgery patients. Chest. 1999;116: 1339-46.

30. Fabregas N, Ewig S, Torres A, El-Ebiary M, Ramirez J, de La Bellacasa JP, et al Clinical diagnosis of ventilator associated pneumonia revisited: comparative validation using immediate post-mortem lung biopsies. Thorax. 1999;54:867-73.

31. Michel F, Franceschini B, Berger P, Arnal JM, Gainnier M, Sainty JM, et al. Early antibiotic treatment for BAL-confirmed ventilator-associated pneumonia: a role for routine endotracheal aspirate cultures. Chest. 2005;127:589-97.

32. Niederman MS. The clinical diagnosis of ventilator-associated pneumonia. Respir Care. 2005;50:788-96; discussion 807-12.

33. Hayon J, Figliolini C, Combes A, Trouillet JL, Kassis N, Dombret MC, et al. Role of serial routine microbiologic culture results in the initial management of ventilator-associated pneumonia. Am J Respir Crit Care Med. 2002;165:41-6.

34. Luna CM, Blanzaco D, Niederman MS, Matarucco W, Baredes NC, Desmery P, et al. Resolution of ventilator-associated pneumonia: prospective evaluation of the clinical pulmonary infection score as an early clinical predictor of outcome. Crit Care Med. 2003;31:676-82.

35. Nseir S, Brisson H, Marquette CH, Chaud P, Di Pompeo C, Diarra M, et al Variations in endotracheal cuff pressure in intubated critically ill patients: prevalence and risk factors. Eur J Anaesthesiol. 2009;26:229-34.

36. Lizy C, Swinnen W, Labeau S, Poelaert J, Dulhunty J, Vogelaers D, et al. Cuff pressure of endotracheal tubes after changes in body position in critically ill patients treated with mechanically ventilation. Am J Crit Care. 2014;23:e1-8. 